\title{
Are we up to date with the NEWS?
}

\author{
Authors: John Blair, James Morgan, Josephine Cassell, Anna Waite and Chiron Velho
}

\section{Aims}

Following several critical incident analyses that involved a failure to recognise the significance of changing NEWS scores, the deteriorating patient group of a district general hospital sought to improve patient safety using a programme of education to increase awareness of good practice.

\section{Methods}

An audit of the current use of NEWS in all clinical areas of the hospital was completed. Audit standards were generated using the Royal College of Physicians report National Early Warning Score (NEWS): Standardising the assessment of acute illness severity in the NHS (2012). Subsequent educational interventions included multidisciplinary bedside teaching, formal training for senior nurses and junior doctors, and an information stand for staff and patients. The NEWS chart was adjusted to make the instructions for managing an elevated score clearer. The audit cycle was completed after 3 months.

\section{Results}

Over 200 patients were included in each audit (201 and 207). The patient demographics assessed were equivalent in both audit samples. Improvements were demonstrated in the following standards (Table 1).

\section{Conclusions}

This project has demonstrated that it is possible to improve the hospital-wide practice of recognising and escalating deteriorating patients using a number of simple and replicable educational interventions. Further improvement is needed, along with an evaluation of the impact on patient outcomes. Future considerations include the introduction of a local electronic solution.

\section{Conflict of interest statement}

We declare that we have no competing interests.

\begin{tabular}{|c|c|c|}
\hline Audit standard & Baseline & 3 months \\
\hline Accuracy of recorded NEWS & $91 \%$ & $98 \%$ \\
\hline $\begin{array}{l}\text { Appropriate escalation of raised NEWS } \\
\text { to critical care outreach nursing team }\end{array}$ & $9 \%$ & $34 \%$ \\
\hline $\begin{array}{l}\text { Appropriate escalation of raised NEWS } \\
\text { to medical team }\end{array}$ & $36 \%$ & $61 \%$ \\
\hline $\begin{array}{l}\text { Adjustment of observation frequency in } \\
\text { relation to previous NEWS }\end{array}$ & $36 \%$ & $53 \%$ \\
\hline Documentation of urine output & $12 \%$ & $30 \%$ \\
\hline $\begin{array}{l}\text { Registered nurse signature for each } \\
\text { recorded NEWS }\end{array}$ & $13 \%$ & $43 \%$ \\
\hline Documented escalation plan & $40 \%$ & $73 \%$ \\
\hline
\end{tabular}

